\title{
Modulation of gastrointestinal vagal neurocircuits by hyperglycemia
}

\author{
Kirsteen N. Browning* \\ Department of Neural and Behavioral Sciences, Penn State College of Medicine, Hershey, PA, USA
}

\section{Edited by:}

Andrea Zsombok, Tulane University, USA

\section{Reviewed by:}

Michael C. Andresen, Oregon

Health and Science University, USA

Bret N. Smith, University of

Kentucky College of Medicine, USA

${ }^{*}$ Correspondence:

Kirsteen N. Browning, Department

of Neural and Behavioral Sciences,

Penn State College of Medicine,

Room 3739B, 500 University Drive,

MC H109, Hershey, PA 17033, USA

e-mail:knb13@psu.edu
Glucose sensing within autonomic neurocircuits is critical for the effective integration and regulation of a variety of physiological homeostatic functions including the co-ordination of vagally-mediated reflexes regulating gastrointestinal (GI) functions. Glucose regulates Gl functions via actions at multiple sites of action, from modulating the activity of enteric neurons, endocrine cells, and glucose transporters within the intestine, to regulating the activity and responsiveness of the peripheral terminals, cell bodies and central terminals of vagal sensory neurons, to modifying both the activity and synaptic responsiveness of central brainstem neurons. Unsurprisingly, significant impairment in Gl functions occurs in pathophysiological states where glucose levels are dysregulated, such as diabetes. A substantial obstacle to the development of new therapies to modify the disease, rather than treat the symptoms, are the gaps in our understanding of the mechanisms by which glucose modulates $\mathrm{Gl}$ functions, particularly vagally-mediated responses and a more complete understanding of disease-related plasticity within these neurocircuits may open new avenues and targets for research.

Keywords: vagus, vagal reflex, afferent, 5-HT, gastric motility

\section{VAGAL REFLEX CONTROL OF GASTROINTESTINAL FUNCTIONS}

Autonomic neurocircuits are vitally important in the integration of homeostatic functions including the co-ordination of vagovagal reflexes regulating gastric motility and emptying, nutrient absorption and satiety signaling. Data from several laboratories, including our own, have demonstrated that a wide variety of gastrointestinal (GI) neurohormones, and neurotransmitters act both centrally and peripherally to modulate vagal neurocircuits regulating GI functions (Dockray, 2004, 2009; Travagli et al., 2006).

Sensory information (mechanical, chemical, osmotic) from the GI tract is transduced and transmitted centrally via the afferent vagus nerve, the cell bodies of which lie in the paired nodose ganglia. While there does not appear to be strict somatotopic organization of neurons within the nodose ganglia there is a trend toward a rostro-caudal viscerotopy where neurons innervating the esophagus are located rostrally while neurons innervating the stomach are located more caudally (Zhuo et al., 1997). The central terminals of these sensory neurons enter the brainstem via the tractus solitarius (TS) and terminate on neurons of the nucleus of the tractus solitarius (NTS) using predominantly glutamate as a neurotransmitter (Andresen and Yang, 1990; Andresen and Kunze, 1994; Baptista et al., 2005). Unlike the nodose ganglion, neurons within the NTS are organized in a viscerotopic manner; activation of gastric vagal afferents, for example, activates neurons within the subnucleus gelatinosus of the NTS, while the subnucleus centralis receives information relating to the sensory control of swallowing (Altschuler et al., 1989, 1991; Barraco et al., 1992; Broussard and Altschuler, 2000). NTS neurons are heterogeneous with respect to their biophysical, neurochemical, and pharmacological properties (Bailey et al., 2002, 2006; Baptista et al., 2005; Browning et al., 2011) which contribute to their integration of this vast volume of sensory afferent information with metabolic and hormonal signals as well as neural inputs from brainstem and other CNS nuclei involved the regulation of autonomic functions. Once assimilated and integrated, NTS neurons relay this information to the adjacent dorsal motor nucleus of the vagus (DMV) which contains the preganglionic parasympathetic motoneurons which provide the output response back to the upper GI tract via the efferent vagus nerve.

In contrast to neurons within the NTS, DMV neurons are not organized viscerotopically but rather in columns or spindles that span the entire rostro-caudal extent of the nucleus related to each of the five subdiaphragmatic vagal branches that innervate the viscera (Shapiro and Miselis, 1985; Jarvinen and Powley, 1999; Travagli et al., 2006). While DMV neurons are also heterogeneous with respect to their biophysical, neurochemical and pharmacological properties (Fox and Powley, 1992; Browning et al., 1999, 2005; Jarvinen and Powley, 1999; Martinez de la Pena y Valenzuela et al., 2004; Babic et al., 2011), as preganglionic parasympathetic neurons they are all a priori cholinergic and activate postganglionic neurons within the target organ of interest via release of acetylcholine to activate nicotinic receptors. Postganglionic neurons within the upper GI tract form two distinct pathways to control gastric functions; an excitatory pathway that increases gastric tone, motility, and secretion via activation of muscarinic cholinergic receptors, and an inhibitory pathway that decreases gastric functions via release of non-adrenergic non-cholinergic (NANC) neurotransmitters, principally nitric 
oxide and vasoactive intestinal polypeptide. Gastric relaxation, therefore, can be achieved by either inhibiting the tonically active cholinergic pathway or by activating the inhibitory NANC pathway (Travagli et al., 2006).

\section{EFFECTS OF GLUCOSE ON GASTROINTESTINAL FUNCTIONS}

Effective glucose sensing is critical for the efficient integration and regulation of a wide variety of physiological functions including the optimal regulation of glycemic levels. One of the most dramatic variations in physiological conditions occurs in response to meal ingestion when blood glucose levels increase dramatically. Glucose exerts profound vagally-mediated effects upon gastric motility and emptying, in part to stabilize excessive fluctuations in blood glucose levels following meal ingestion (MacGregor et al., 1976; Horowitz and Fraser, 1994; Ferreira et al., 2001; Rayner et al., 2001; Ishiguchi et al., 2002; Shi et al., 2003; Zhou et al., 2008). An increase in gastric motility in response to hypoglycemia accelerates nutrient delivery to the intestine allowing increased absorption and re-establishes plasma glucose levels whereas a hyperglycemia-induced decrease in gastric motility delays gastric emptying and reduces further glucose absorption preventing potentially prolonged, and damaging, elevations in glycemic levels.

Glucose is known to directly alter the activity of enteric nervous system neurons; intraintestinal infusions of glucose not only activates predominantly sensory neurons in the myenteric and submucosal plexuses of the upper small intestine (Liu et al., 1999; Sayegh et al., 2004; Vincent et al., 2011), it also appears to modulate the response of enteric neurons to other GI neurohormones such as cholecystokinin and serotonin (Roosen et al., 2012). Glucose appears to decrease gastric motility and delays gastric emptying primarily via indirect (paracrine) mechanisms of action, however. Glucose within the lumen of the intestine induces the release of neurohormones from enteroendocrine cells including releasing 5-HT from enterochromaffin cells within the proximal intestine as well as GLP-1 from L-cells in the distal intestine. These released neurohormones activate receptors (5-HT3 and GLP-1 receptors, respectively) on peripheral GI vagal afferent fiber terminals and the resulting excitatory signals are relayed centrally (Raybould, 1998, 1999, 2002; Glatzle et al., 2002; Raybould et al., 2003; Vincent et al., 2011). These sensory signals activate second order neurons within the NTS and, following integration, the subsequent vagal motor response induces gastric relaxation and delayed emptying (Zittel et al., 1994; Ferreira et al., 2001; Raybould et al., 2003; Zhou et al., 2008; Hayes et al., 2010; Vincent et al., 2011).

The vagal efferent pathway responsible for this glucoseinduced gastric inhibition is somewhat controversial, however. Studies in rats have demonstrated that, within the brainstem, increasing extracellular glucose levels decreases gastric motility via inhibition of the excitatory cholinergic pathway rather than activation of the inhibitory NANC pathway (Ferreira et al., 2001; Shi et al., 2005) whereas other studies have suggested that the gastric relaxation induced following peripheral hyperglycemia was abolished by nitric oxide and VIP antagonists, suggesting that activation of the inhibitory NANC pathway was involved (Zhou et al., 2008). While differences in experimental protocols may account for some of these differences, it is unlikely to explain fully such divergent results. It is possible that different vagal efferent pathways are engaged by peripheral vs. central glucose, although this remains to be elucidated.

\section{EFFECTS OF GLUCOSE ON VAGAL AFFERENT NEURONS}

Once absorbed, however, glucose enters the bloodstream from where it continues to exert profound effects upon vagal neurocircuits controlling GI functions. While glucose increases the firing rate of vagal afferent fibers innervating the GI tract (Mei, 1978, 1985), it has also been known for some time that the responses of vagal afferents to intra-intestinal glucose is modulated by intravenous glucose (Mei, 1978) suggesting that circulating glucose may also modulate the activity and responsiveness of vagal sensory neurons.

Despite being contained within the relatively tough capsule of the nodose ganglion, vagal sensory neurons appear to be accessible to circulating factors (Lacolley et al., 2006a,b). While glucose is a universal fuel for neurons, some neurons possess the additional ability of using variations in extracellular glucose levels as a means of altering their excitability (Adachi et al., 1995; Levin et al., 2001; Kang et al., 2006). A subpopulation of vagal sensory neurons appears to display this sensitivity and are either excited or inhibited by elevations in glucose levels (Grabauskas et al., 2010). Further, the response to glucose appears to be related to the visceral organ that the vagal sensory neurons innervate; afferent neurons projecting to the stomach are more likely to exhibit excitatory responses to elevations in glucose levels while those that innervate the portal vein were more likely to be inhibitory in response to an increase in glucose, suggesting that the effects of glucose on vagal sensory transmission are specialized relative to the visceral information they transmit (Grabauskas et al., 2010). As with other neurons excited by elevations in glucose levels, this activation appears to involve the closure of an ATP-sensitive potassium channel (Dunn-Meynell et al., 1998; Ferreira et al., 2001; Raupach and Ballanyi, 2004; Balfour and Trapp, 2007; Grabauskas et al., 2010) while inhibition of vagal sensory neurons by glucose appears to involve an ATP-insensitive potassium channel although the ionic current involved remains to be elucidated (Grabauskas et al., 2010).

In addition to direct actions upon vagal afferent neurons, glucose also exerts indirect actions via modulation of neurotransmitter receptor density on the neuronal surface. In particular, we have demonstrated recently that glucose induces trafficking of $5-\mathrm{HT}_{3}$ receptors in GI vagal afferent neurons; following an increase in glucose levels, $5-\mathrm{HT}_{3}$ receptors are trafficked to the neuronal membrane (Babic et al., 2012). In contrast, a decrease in glucose levels results in receptor internalization (Babic et al., 2012). The functional consequence of this glucose-induced receptor trafficking is an increase or decrease in the inward current induced by 5 -HT in response to an elevation or reduction of extracellular glucose level (Babic et al., 2012). Importantly, this glucose-induced modulation of $5-\mathrm{HT}_{3}$ receptor function occurs rapidly (within minutes) suggesting that, in addition to inducing the release of 5-HT from enterochromaffin cells, glucose may also increase the ability of GI vagal afferent neurons to respond 
to released 5-HT. In this regard, it is also notable that, following the glucose-induced release of GI neurohormones and their activation of vagal afferent terminals within the intestine, these neurohormones also enter the circulation and gain access to vagal afferent neurons; circulating levels of platelet free 5-HT increase approximately 3 -fold after meal ingestion (Houghton et al., 2003). Thus, the glucose-induced modulation of $5-\mathrm{HT}_{3}$ receptor density and function on vagal afferent neurons appears to be a means by which sensory signaling from the GI tract can be amplified or prolonged.

\section{EFFECTS OF GLUCOSE ON CENTRAL VAGAL NEUROCIRCUITS}

In addition to modulating the activity and functions of vagal sensory neurons and peripheral terminals, glucose also modulates the release of neurotransmitter from the central terminals of vagal sensory neurons; increasing the extracellular glucose concentration increased action potential-dependent and -independent glutamate release onto second order NTS neurons, while decreasing extracellular glucose levels inhibited glutamate release (Wan and Browning, 2008a). Further studies demonstrated that, as with vagal sensory somata, glucose induces the trafficking of 5-HT3 receptors to the membrane of vagal sensory nerve terminals, the activation of which increases glutamate release (Wan and Browning, 2008b). 5- $\mathrm{HT}_{3}$ receptors on vagal afferent terminals appear to be activated tonically; in fact, the $5-\mathrm{HT}_{3}$ receptor antagonist, ondansetron, decreases action potential dependent and independent synaptic transmission to second order NTS neurons implying an ongoing activation of these receptors (Wan and Browning, 2008b). The NTS receives a dense serotonergic input from other brainstem nuclei, most prominently the medullary raphe nuclei (Steinbusch, 1981; Steinbusch and Nieuwenhuys, 1981; Thor and Helke, 1989) although vagal afferent neurons themselves contain 5-HT (Nosjean et al., 1990; Sykes et al., 1994).

Early studies using extracellular recording techniques showed that glucose is able to modulate the activity of subpopulations of neurons within the brainstem. Hepatic vagal afferent fibers that showed a decrease in activity in response to increased glucose exposure, for example, innervate NTS neurons that are also inhibited by local application of glucose (Adachi et al., 1984). Other NTS neurons, in contrast, increased their activity in response to elevated glucose levels (Adachi et al., 1995; Yettefti et al., 1995, 1997; Dallaporta et al., 2000); as described earlier for vagal sensory neurons, as well as for other glucose-sensitive central neurons (Dunn-Meynell et al., 1998; Levin et al., 2001), this increase in neuronal activity in response to increased extracellular glucose levels appear to involve ATP-sensitive potassium channels (Dallaporta et al., 2000; Balfour et al., 2006; Balfour and Trapp, 2007). The mechanism responsible for glucose-induced neuronal inhibition awaits further study, although modulation of chloride conductances may be involved (Balfour and Trapp, 2007).

The ability of glucose to modulate the activity of DMV neurons is more controversial, however. An earlier study using extracellular recording techniques suggested that a small subpopulation of DMV neurons that project via the ventral, or anterior, gastric branch increased or decreased their activity in response to topical glucose administration (Kobashi and
Adachi, 1994; Adachi et al., 1995). Other studies using whole cell patch clamp recording techniques confirmed the presence of ATP-sensitive potassium channels on DMV neurons (Trapp et al., 1994; Karschin et al., 1998; Ferreira et al., 2001; Kulik et al., 2002; Raupach and Ballanyi, 2004; Balfour et al., 2006; Balfour and Trapp, 2007; Blake and Smith, 2012) suggesting their activity may be modulated by extracellular glucose levels. In contrast, later studies failed to observe any direct effects of glucose on DMV neuronal activity but, rather, demonstrated indirect effects via modulation of synaptic inputs presumably from NTS neurons (Ferreira et al., 2001). In part, these studies highlight the potential difficulties in separating direct from indirect effects when recording from neurons in brain slice preparations and the additional care required when examining ATP-sensitive potassium channels in neurons (to prevent unintentional channel closure via ATP supplied in the intracellular patch pipette solution).

One important caveat to the studies investigating the role of glucose within the brainstem is the concentration or dose of extracellular glucose used in most studies, which almost certainly exceeds physiological levels. Extracellular glucose levels in most CNS regions are assumed to be $15-20 \%$ of peripheral levels; hypothalamic glucose levels certainly vary in concert with blood glucose levels, but they do so within a very narrow range ( 0.25-1.0 mM; Dunn-Meynell et al., 2009) although other studies have measured cortical glucose levels between 0.2 and $4.5 \mathrm{mM}$ (Silver and Erecinska, 1994). It should be borne in mind, however, that brainstem vagal neurons may be exposed to higher glucose levels than many other central nuclei since they are essentially circumventricular organs with a leaky blood-brain barrier and fenestrated capillaries (Cottrell and Ferguson, 2004). Regardless, our laboratory has demonstrated recently that, even at similarly low (0.5-5 mM, presumably more physiological) levels, glucose modulates glutamate release from the central terminals of vagal afferent neurons onto second order NTS neurons (Figure 1; Browning, unpublished data). This would suggest that the central terminals of some GI vagal sensory neurons may function as glucose sensors, in the sense that extracellular glucose levels regulate neurotransmitter release in a linear fashion across both physiological and pathophysiological ranges (Wan and Browning, 2008a).

\section{ALTERATIONS IN ACTIONS OF GLUCOSE ON VAGALLY- MEDIATED GASTROINTESTINAL REFLEXES DURING PATHOPHYSIOLOGICAL STATES}

As described earlier, GI functions including gastric motility and emptying are modulated by physiological alterations in blood glucose levels (Rayner et al., 2001). It is hardly surprising, therefore, that pathophysiological alterations in glucose levels result in profound disruption of GI functions. Although gastric hyperactivity has been observed in some rodent models of hyperglycemia and is experienced by some patients with diabetes, a significant proportion of animal models as well as patients exhibit diabetic gastroparesis, defined as delayed gastric emptying accompanied by other upper GI symptoms such as early satiety, fullness, abdominal pain, bloating, and nausea (Horowitz et al., 2002; Chaikomin et al., 2006). The severity of diabetic gastroparesis can vary widely from symptoms of mild discomfort up to 


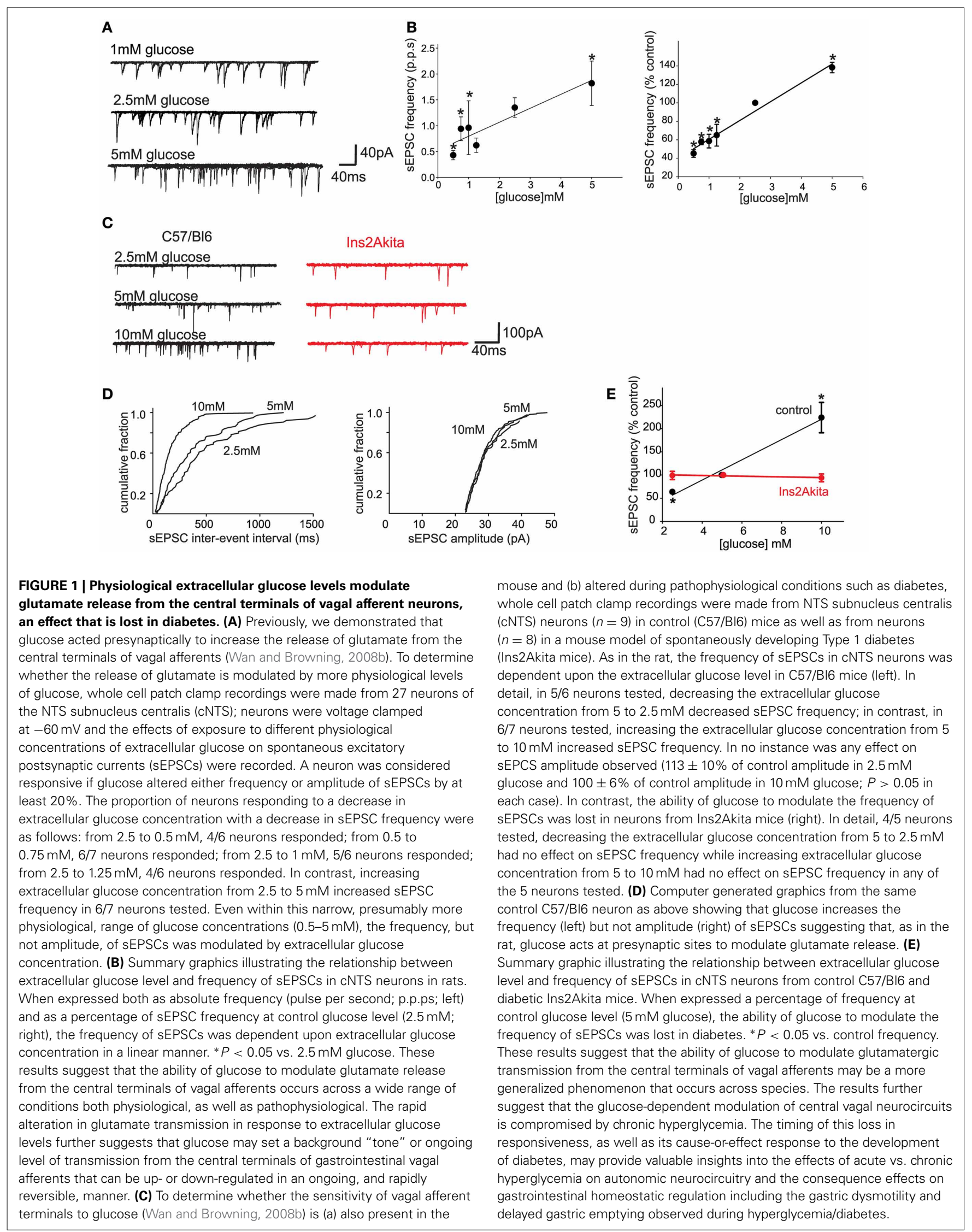


impaired glycemic control, electrolyte imbalance, and malnutrition (Horowitz et al., 2002; Chaikomin et al., 2006). Despite the considerable healthcare and social costs associated with this disease, the pathophysiology of diabetic gastroparesis remains to be elucidated fully. That both Type 1 and Type 2 diabetic patients experience gastroparesis symptoms suggests that hyperglycemia, or dysregulated glycemic control per se, may play an important role in symptom development, although insulin itself certainly modulates the activity of central vagal motoneurons (Blake and Smith, 2012) and induces vagally-mediated increases in gastric motility (Krowicki et al., 1998).

The GI dysfunctions induced by either Type 1 or Type 2 diabetes may occur through actions at multiple sites (Figure 2). A loss of enteric neurons neurons, particularly inhibitory neurons (nitric oxide synthase-, vasoactive intestinal peptide-, neuropeptide $\mathrm{Y}$ - and galanin-immunoreactive) has been reported in rodent models of both Type 1 and Type 2 diabetes during the early stages of the disease [reviewed in Chandrasekharan and Srinivasan
(2007)] which may contribute to the observed disordered motility patterns and decreased NANC-dependent muscle relaxations (Jenkinson and Reid, 2000; Yoneda et al., 2001; Demedts et al., 2013). Loss of Inhibitory Cells of Cajal (ICC) has also been reported in both Type 1 and Type 2 diabetes (Ordog et al., 2000; He et al., 2001; Iwasaki et al., 2006; Forrest et al., 2008; Wang et al., 2009; Grover et al., 2011) suggesting this may be another important means by which persistant hyperglycemia dysregulates GI motility although reduced levels of insulin and insulin signaling, rather than hyperglycemia per se, has also been shown to be involved in ICC depletion (Horvath et al., 2005).

Glucose sensing within enteroendocrine cells is also disrupted in diabetes (Lee et al., 2012) as are both the basal expression and function of intestinal sodium-glucose transporters (Bihler and Freund, 1975; Morton and Hanson, 1984; Dyer et al., 2002; Bhutta et al., 2013) suggesting that the increased absorption of glucose further amplifies the disrupted and dysregulated responses of GI neurocircuits to glucose. It is hardly surprising, therefore,

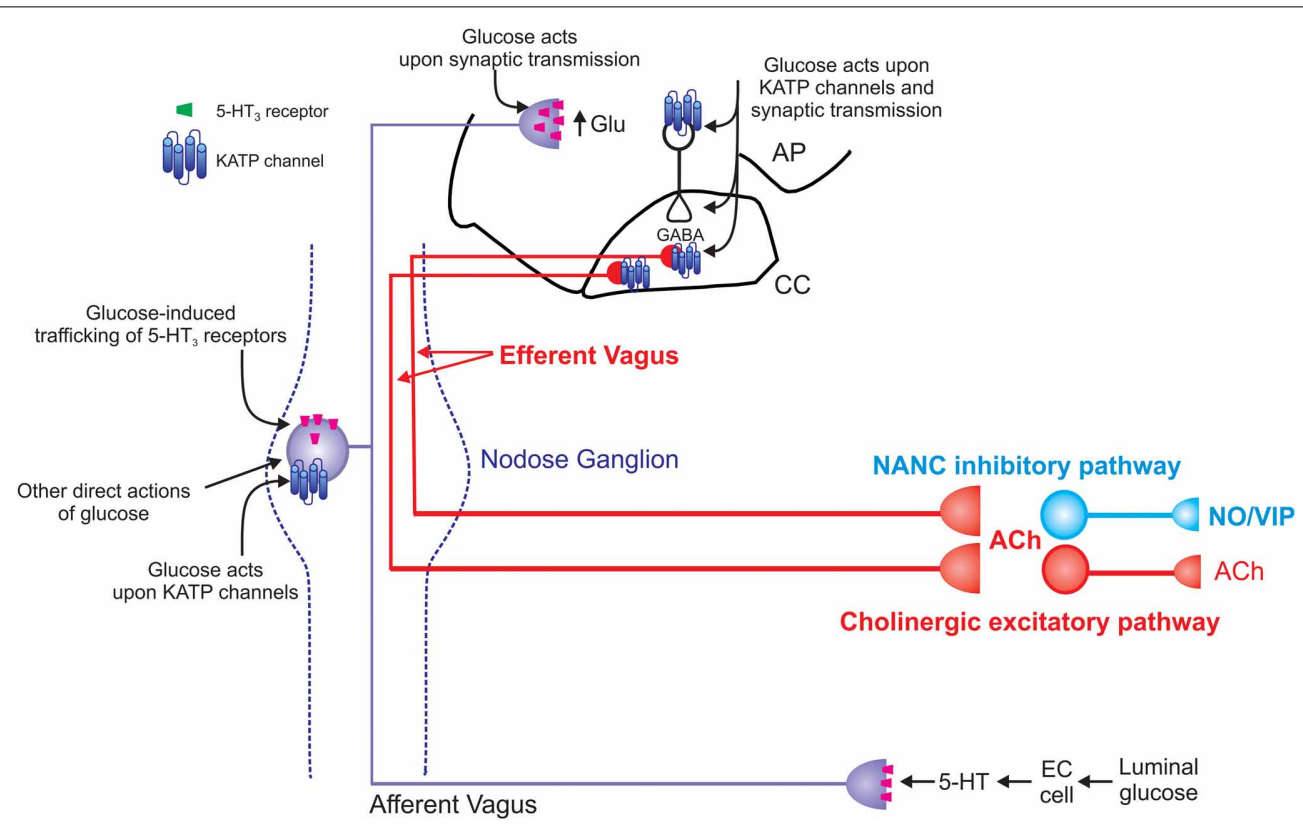

FIGURE 2 | Schematic representation of the effects of glucose on vago-vagal reflex control of the stomach. Glucose within the intestine induces the release of serotonin from enteroendocrine (EC) cells (Zhu et al., 2001; Freeman et al., 2006). The released 5-HT acts upon 5-HT3 receptors present on the peripheral terminals of vagal afferent neurons to cause their excitation (Hillsley et al., 1998; Raybould et al., 2003; Grundy, 2006); this peripheral signal is relayed centrally via the afferent vagus nerve. Once absorbed into the circulation, glucose is also able to act directly upon vagal afferent neurons within the nodose ganglion. Glucose induces neuronal excitation via actions upon ATP-sensitive potassium channels (KATP channels; Grabauskas et al., 2010) as well as causing neuronal inhibition via an as yet unidentified mechanism (Grabauskas et al., 2010). Glucose also rapidly and reversibly traffics 5-HT3 receptors to and from the membrane of gastrointestinal vagal afferent neurons (Babic et al., 2012). Since circulating platelet-free 5-HT levels increase following ingestion of a meal (Houghton et al., 2003), this provides a means by which glucose is able to modulate its own "perception" and amplify or prolong vagal afferent signaling. The central terminals of vagal afferent neurons enter the brainstem via the tractus solitarius and terminate on NTS neurons using predominantly glutamate as a neurotransmitter (Andresen and Yang, 1990; Andresen and Kunze, 1994). Glucose is also able to modulate the release of glutamate from the central terminals of vagal afferents by actions that involve 5-HT3 receptors (Wan and Browning, 2008a,b). Glucose can also activate NTS neurons via actions on KATP channels and increase synaptic transmission to gastric-projecting DMV neurons (Adachi et al., 1984, 1995; Ferreira et al., 2001). Glucose can also modulate the activity of DMV neurons directly (Trapp et al., 1994; Karschin et al., 1998; Balfour et al., 2006; Balfour and Trapp, 2007). The result of these central and peripheral actions of glucose is gastric relaxation and delayed gastric emptying (Schvarcz et al., 1997; Raymer et al., 2000; Rayner et al., 2001). The vagal efferent pathway involved in this gastric relaxation and delayed gastric emptying is still controversial. Peripheral actions of glucose appear to involve activation of a non-adrenergic, non-cholinergic pathway (Zhou et al., 2008) whereas central glucose appears to involve inhibition of the tonically active cholinergic pathway (Ferreira et al., 2001; Shi et al., 2003, 2005). 
that altered vagal sensory and motor fiber functions have been reported in both humans (Tougas et al., 1992) and rodent models of diabetes (Yagihashi and Sima, 1986; Lee et al., 2001, 2012; Regalia et al., 2002). While frank autonomic neuropathy almost certainly contributes to the altered vagal sensory and motor functions observed in chronic diabetes, the actions of acute hyperglycemia to modulate vagal afferent and efferent functions (MacGregor et al., 1976; Shi et al., 2003; Takahashi et al., 2003; Zhou et al., 2008) suggests that poor glycemic control per se also negatively impacts vagal reflex functions.

While diabetes is most often considered a peripheral metabolic disease, an increasing body of evidence indicates a significant involvement of the central nervous system, including vagal neurocircuits within the hindbrain, in its development and functional outcomes. In a mouse model of spontaneously developing Type 1 diabetes, the Ins2(Akita) mouse, the ability of glucose to modulate synaptic transmission to second order NTS neurons is lost (see Figures 1C,D; Browning, unpublished data) suggesting an impairment of glucose sensitivity within vagal sensory neurocircuits. Recent studies have demonstrated that even short time periods of glycemic dysregulation result in significant modulation of synaptic transmission within vagal neurocircuits (Zsombok et al., 2011). This would suggest that the vagal control of GI functions may by disrupted even in the early stages of glycemic dysregulation, rather than as a consequence of autonomic neuropathy. In this regard, preliminary evidence that even short periods of exposure to a high fat diet disrupts the glucose-induced trafficking of $5-\mathrm{HT}_{3}$ receptors on GI vagal sensory neurons, well in advance of the development of obesity or hyperglycemia (Troy and Browning, 2013), raises the possibility that altered glucose signaling within vagal neurocircuits may precede, and even contribute to, disease development.

\section{FUTURE DIRECTIONS}

Glucose sensing within autonomic neurocircuits is critical for the effective integration and regulation of a variety of physiological homeostatic functions involved in the optimal regulation of blood glucose levels, including the co-ordination of vagallymediated reflexes regulating GI functions (e.g., gastric motility and emptying, nutrient absorption and satiety signaling). Glucose regulates GI functions via actions at multiple sites of action, from modulating the activity of enteric neurons, endocrine cells and glucose transporters within the intestine, to regulating the activity and responsiveness of the peripheral terminals, cell bodies and central terminals of vagal sensory neurons, to modifying both the activity and synaptic responsiveness of NTS and DMV neurons. Unsurprisingly, significant impairment in GI functions results occurs in pathophysiological states where glucose levels are dysregulated, such as diabetes. A substantial obstacle to the development of new therapies to modify the disease, rather than treat the symptoms, are the gaps in our understanding of the mechanisms by which glucose modulates GI functions, particularly vagally-mediated responses. Vagal afferent and efferent fibers represent a much more readily available target for new therapies and a more complete understanding of disease-related plasticity within these neurocircuits may open new avenues and targets for research.
It will be of particular interest to elucidate the reversibility of hyperglycemia- and diabetes-induced vagal dysregulation-is there a period of exposure to hyperglycemia beyond which vagal neural damage is irreversible or is the neurocircuitry sufficiently plastic to recover with subsequent tight glycemic control? In this regard, the recent demonstration that the diet-induced obesity associated decrease in excitability and responsiveness of vagal motoneurons is reversed completely by Roux-en-Y gastric bypass surgery (Browning et al., 2013) suggests that vagal neurocircuits remain open to adaptation and that long-term dysregulation of their activity does not necessarily result in permanent and irrecoverable damage. The rapid remission of Type 2 diabetes following bariatric surgery, far in advance of weight loss, raises questions as to its mechanism of action and the degree to which recovery of glycemic regulation is related to the recovery of vagal afferent and efferent homeostatic control.

\section{ACKNOWLEDGMENTS}

Funding was provided by NIH DK078364 to Kirsteen N. Browning. The author thanks Dr R. Alberto Travagli for critical reviews of earlier versions of this manuscript and W.Nairn Browning for support and encouragement.

\section{REFERENCES}

Adachi, A., Kobashi, M., and Funahashi, M. (1995). Glucose-responsive neurons in the brainstem. Obes. Res. 3 Suppl 5, 735S-740S. doi: 10.1002/j.15508528.1995.tb00493.x

Adachi, A., Shimizu, N., Oomura, Y., and Kobashi, M. (1984). Convergence of hepatoportal glucose-sensitive afferent signals to glucose-sensitive units within the nucleus of the solitary tract. Neurosci. Lett. 46, 215-218. doi: 10.1016/03043940(84)90444-0

Altschuler, S. M., Bao, X., Bieger, D., Hopkins, D. A., and Miselis, R. R. (1989). Viscerotopic representation of the upper alimentary tract in the rat: sensory ganglia and nuclei of the solitary and spinal trigeminal tracts. J. Comp. Neurol. 283, 248-268. doi: 10.1002/cne.902830207

Altschuler, S. M., Ferenci, D. A., Lynn, R. B., and Miselis, R. R. (1991). Representation of the cecum in the lateral dorsal motor nucleus of the vagus nerve and commissural subnucleus of the nucleus tractus solitarii in rat. J. Comp. Neurol. 304, 261-274. doi: 10.1002/cne.903040209

Andresen, M. C., and Kunze, D. L. (1994). Nucleus tractus solitariusgateway to neural circulatory control. Annu. Rev. Physiol. 56, 93-116. doi: 10.1146/annurev.physiol.56.1.93

Andresen, M. C., and Yang, M. (1990). Non-NMDA receptors mediate sensory afferent synaptic transmission in medial nucleus tractus solitarius. Am. J. Physiol. 259, H1307-H1311.

Babic, T., Browning, K. N., and Travagli, R. A. (2011). Differential organization of excitatory and inhibitory synapses within the rat dorsal vagal complex. Am. J. Physiol. Gastrointest. Liver Physiol. 300, G21-G32. doi: 10.1152/ajpgi.00363.2010

Babic, T., Troy, A. E., Fortna, S. R., and Browning, K. N. (2012). Glucosedependent trafficking of 5-HT(3) receptors in rat gastrointestinal vagal afferent neurons. Neurogastroenterol. Motil. 24, e476-e488. doi: 10.1111/j.13652982.2012.01987.x

Bailey, T. W., Hermes, S. M., Andresen, M. C., and Aicher, S. A. (2006). Cranial visceral afferent pathways through the nucleus of the solitary tract to caudal ventrolateral medulla or paraventricular hypothalamus: target-specific synaptic reliability and convergence patterns. J. Neurosci. 26, 11893-11902. doi: 10.1523/JNEUROSCI.2044-06.2006

Bailey, T. W., Jin, Y. H., Doyle, M. W., and Andresen, M. C. (2002). Vanilloidsensitive afferents activate neurons with prominent A-type potassium currents in nucleus tractus solitarius. J. Neurosci. 22, 8230-8237.

Balfour, R. H., Hansen, A. M., and Trapp, S. (2006). Neuronal responses to transient hypoglycaemia in the dorsal vagal complex of the rat brainstem. J. Physiol. 570, 469-484. doi: 10.1113/jphysiol.2005.098822 
Balfour, R. H., and Trapp, S. (2007). Ionic currents underlying the response of rat dorsal vagal neurones to hypoglycaemia and chemical anoxia. J. Physiol. 579, 691-702. doi: 10.1113/jphysiol.2006.126094

Baptista, V., Zheng, Z. L., Coleman, F. H., Rogers, R. C., and Travagli, R. A. (2005). Characterization of neurons of the nucleus tractus solitarius pars centralis. Brain Res. 1052, 139-146. doi: 10.1016/j.brainres.2005.05.073

Barraco, R., el-Ridi, M., Ergene, E., Parizon, M., and Bradley, D. (1992). An atlas of the rat subpostremal nucleus tractus solitarius. Brain Res. Bull. 29, 703-765. doi: 10.1016/0361-9230(92)90143-L

Bhutta, H. Y., Deelman, T. E., Ashley, S. W., Rhoads, D. B., and Tavakkoli, A. (2013). Disrupted circadian rhythmicity of the intestinal glucose transporter SGLT1 in Zucker diabetic fatty rats. Dig. Dis. Sci. 58, 1537-1545. doi: 10.1007/s10620-0132669-y

Bihler, I., and Freund, N. (1975). Sugar transport in the small intestine of obese hyperglycemic, fed and fasted mice. Diabetologia 11, 387-393. doi: 10.1007/BF00429905

Blake, C. B., and Smith, B. N. (2012). Insulin reduces excitation in gastric-related neurons of the dorsal motor nucleus of the vagus. Am. J. Physiol. Regul. Integr. Comp. Physiol. 303, R807-R814. doi: 10.1152/ajpregu.00276.2012

Broussard, D. L., and Altschuler, S. M. (2000). Central integration of swallow and airway-protective reflexes. Am. J. Med. 108(Suppl. 4a), 62S-67S. doi: 10.1016/S0002-9343(99)00340-X

Browning, K. N., Coleman, F. H., and Travagli, R. A. (2005). Characterization of pancreas-projecting rat dorsal motor nucleus of vagus neurons. Am. J. Physiol. Gastrointest. Liver Physiol. 288, G950-G955. doi: 10.1152/ajpgi.00549.2004

Browning, K. N., Fortna, S. R., and Hajnal, A. (2013). Roux-en-Y gastric bypass reverses the effects of diet-induced obesity to inhibit the responsiveness of central vagal motoneurones. J. Physiol. 591, 2357-2372. doi: 10.1113/jphysiol.2012.249268

Browning, K. N., Renehan, W. E., and Travagli, R. A. (1999). Electrophysiological and morphological heterogeneity of rat dorsal vagal neurones which project to specific areas of the gastrointestinal tract. J. Physiol. 517, 521-532. doi: 10.1111/j.1469-7793.1999.0521t.x

Browning, K. N., Wan, S., Baptista, V., and Travagli, R. A. (2011). Vanilloid, purinergic, and CCK receptors activate glutamate release on single neurons of the nucleus tractus solitarius centralis. Am. J. Physiol. Regul. Integr. Comp. Physiol. 301, R394-R401. doi: 10.1152/ajpregu.00054.2011

Chaikomin, R., Rayner, C. K., Jones, K. L., and Horowitz, M. (2006). Upper gastrointestinal function and glycemic control in diabetes mellitus. World J. Gastroenterol. 12, 5611-5621.

Chandrasekharan, B., and Srinivasan, S. (2007). Diabetes and the enteric nervous system. Neurogastroenterol. Motil. 19, 951-960. doi: 10.1111/j.13652982.2007.01023.x

Cottrell, G. T., and Ferguson, A. V. (2004). Sensory circumventricular organs: central roles in integrated autonomic regulation. Regul. Pept. 117, 11-23. doi: 10.1016/j.regpep.2003.09.004

Dallaporta, M., Perrin, J., and Orsini, J.-C. (2000). Involvement of adenosine triphosphate-sensitive $\mathrm{K}^{+}$channels in glucose-sensing in the rat solitary tract nucleus. Neurosci. Lett. 278, 77-80. doi: 10.1016/S0304-3940(99) 00898-8

Demedts, I., Masaoka, T., Kindt, S., De, H. G., Geboes, K., Farre, R., et al. (2013). Gastrointestinal motility changes and myenteric plexus alterations in spontaneously diabetic biobreeding rats. J. Neurogastroenterol. Motil. 19, 161-170. doi: 10.5056/jnm.2013.19.2.161

Dockray, G. (2004). Gut endocrine secretions and their relevance to satiety. Curr. Opin. Pharmacol. 4, 557-560. doi: 10.1016/j.coph.2004.05.005

Dockray, G. J. (2009). The versatility of the vagus. Physiol. Behav. 97, 531-536. doi: 10.1016/j.physbeh.2009.01.009

Dunn-Meynell, A. A., Rawson, N. E., and Levin, B. E. (1998). Distribution and phenotype of neurons containing the ATP-sensitive $\mathrm{K}^{+}$channel in rat brain. Brain Res. 814, 41-54. doi: 10.1016/S0006-8993(98)00956-1

Dunn-Meynell, A. A., Sanders, N. M., Compton, D., Becker, T. C., Eiki, J., Zhang, B. B., et al. (2009). Relationship among brain and blood glucose levels and spontaneous and glucoprivic feeding. J. Neurosci. 29, 7015-7022. doi: 10.1523/JNEUROSCI.0334-09.2009

Dyer, J., Wood, I. S., Palejwala, A., Ellis, A., and Shirazi-Beechey, S. P. (2002). Expression of monosaccharide transporters in intestine of diabetic humans. Am. J. Physiol. Gastrointest. Liver Physiol. 282, G241-G248. doi: 10.1152/ajpgi.00310.2001
Ferreira, M. Jr., Browning, K. N., Sahibzada, N., Verbalis, J. G., Gillis, R. A., and Travagli, R. A. (2001). Glucose effects on gastric motility and tone evoked from the rat dorsal vagal complex. J. Physiol. 536, 141-152. doi: 10.1111/j.14697793.2001.t01-1-00141.x

Forrest, A., Huizinga, J. D., Wang, X. Y., Liu, L. W., and Parsons, M. (2008). Increase in stretch-induced rhythmic motor activity in the diabetic rat colon is associated with loss of ICC of the submuscular plexus. Am. J. Physiol. Gastrointest. Liver Physiol. 294, G315-G326. doi: 10.1152/ajpgi.00196.2007

Fox, E. A., and Powley, T. L. (1992). Morphology of identified preganglionic neurons in the dorsal motor nucleus of the vagus. J. Comp. Neurol. 322, 79-98. doi: $10.1002 /$ cne. 903220107

Freeman, S. L., Bohan, D., Darcel, N., and Raybould, H. E. (2006). Luminal glucose sensing in the rat intestine has characteristics of a sodium-glucose cotransporter. Am. J. Physiol. Gastrointest. Liver Physiol. 291, G439-G445. doi: 10.1152/ajpgi.00079.2006

Glatzle, J., Sternini, C., Robin, C., Zittel, T. T., Wong, H., Reeve, J. R. Jr., et al. (2002). Expression of 5-HT3 receptors in the rat gastrointestinal tract. Gastroenterology 123, 217-226. doi: 10.1053/gast.2002.34245

Grabauskas, G., Song, I., Zhou, S. Y., and Owyang, C. (2010). Electrophysiological identifications of glucose-sensing neurons in the rat nodose ganglia. J. Physiol. 588, 617-632. doi: 10.1113/jphysiol.2009.182147

Grover, M., Farrugia, G., Lurken, M. S., Bernard, C. E., Faussone-Pellegrini, M. S., Smyrk, T. C., et al. (2011). Cellular changes in diabetic and idiopathic gastroparesis. Gastroenterology 140, 1575-1585. doi: 10.1053/j.gastro.2011.01.046

Grundy, D. (2006). Serotonin and sensory signalling from the gastrointestinal lumen. J. Physiol. 575, 1-2. doi: 10.1113/jphysiol.2006.113472

Hayes, M. R., De Jonghe, B. C., and Kanoski, S. E. (2010). Role of the glucagonlike-peptide-1 receptor in the control of energy balance. Physiol. Behav. 100, 503-510. doi: 10.1016/j.physbeh.2010.02.029

He, C. L., Soffer, E. E., Ferris, C. D., Walsh, R. M., Szurszewski, J. H., and Farrugia, G. (2001). Loss of interstitial cells of cajal and inhibitory innervation in insulin-dependent diabetes. Gastroenterology 121, 427-434. doi: 10.1053/gast.2001.26264

Hillsley, K., Kirkup, A. J., and Grundy, D. (1998). Direct and indirect actions of 5-hydroxytryptamine on the discharge of mesenteric afferent fibres innervating the rat jejunum. J. Physiol. 506(Pt 2), 551-561. doi: 10.1111/j.14697793.1998.551bw.x

Horowitz, M., and Fraser, R. (1994). Disordered gastric motor function in diabetes mellitus. Diabetologia 37, 543-551. doi: 10.1007/BF00403371

Horowitz, M., O’Donovan, D., Jones, K. L., Feinle, C., Rayner, C. K., and Samsom, M. (2002). Gastric emptying in diabetes: clinical significance and treatment. Diabet. Med. 19, 177-194. doi: 10.1046/j.1464-5491.2002.00658x

Horvath, V. J., Vittal, H., and Ordog, T. (2005). Reduced insulin and IGF-I signaling, not hyperglycemia, underlies the diabetes-associated depletion of interstitial cells of Cajal in the murine stomach. Diabetes 54, 1528-1533. doi: 10.2337/diabetes.54.5.1528

Houghton, L. A., Atkinson, W., Whitaker, R. P., Whorwell, P. J., and Rimmer, M. J. (2003). Increased platelet depleted plasma 5-hydroxytryptamine concentration following meal ingestion in symptomatic female subjects with diarrhoea predominant irritable bowel syndrome. Gut 52, 663-670. doi: 10.1136/gut.52. 5.663

Ishiguchi, T., Tada, H., Nakagawa, K., Yamamura, T., and Takahashi, T. (2002). Hyperglycemia impairs antro-pyloric coordination and delays gastric emptying in conscious rats. Auton. Neurosci. 95, 112-120. doi: 10.1016/S15660702(01)00383-6

Iwasaki, H., Kajimura, M., Osawa, S., Kanaoka, S., Furuta, T., Ikuma, M., and Hishida, A. (2006). A deficiency of gastric interstitial cells of Cajal accompanied by decreased expression of neuronal nitric oxide synthase and substance $\mathrm{P}$ in patients with type 2 diabetes mellitus. J. Gastroenterol. 41, 1076-1087. doi: 10.1007/s00535-006-1909-8

Jarvinen, M. K., and Powley, T. L. (1999). Dorsal motor nucleus of the vagus neurons: a multivariate taxonomy. J. Comp. Neurol. 403, 359-377.

Jenkinson, K. M., and Reid, J. J. (2000). Altered non-adrenergic non-cholinergic neurotransmission in gastric fundus from streptozotocin-diabetic rats. Eur. J. Pharmacol. 401, 251-258. doi: 10.1016/S0014-2999(00)00280-6

Kang, L., Dunn-Meynell, A. A., Routh, V. H., Gaspers, L. D., Nagata, Y., Nishimura, T., et al. (2006). Glucokinase is a critical regulator of ventromedial hypothalamic neuronal glucosensing. Diabetes 55, 412-420. doi: 10.2337/diabetes.55.02.06.db05-1229 


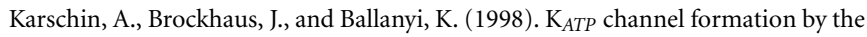
sulphonylurea receptors SUR1 with Kir6.2 subunits in rat dorsal vagal neurons in situ. J. Physiol. 509, 339-346. doi: 10.1111/j.1469-7793.1998.339bn.x

Kobashi, M., and Adachi, A. (1994). Effect of topical administration of glucose on neurons innervating abdominal viscera in dorsal motor nucleus of vagus in rats. Jpn. J. Physiol. 44, 729-734. doi: 10.2170/jjphysiol.44.729

Krowicki, Z. K., Nathan, N. A., and Hornby, P. J. (1998). Gastric motor and cardiovascular effects of insulin in dorsal vagal complex of the rat. Am. J. Physiol. 275, G964-G972.

Kulik, A., Brockhaus, J., Pedarzani, P., and Ballanyi, K. (2002). Chemical anoxia activates ATP-sensitive and blocks $\mathrm{Ca}(2+)$-dependent $\mathrm{K}(+)$ channels in rat dorsal vagal neurons in situ. Neuroscience 110, 541-554. doi: 10.1016/S03064522(01)00468-7

Lacolley, P., Owen, J. R., Sandock, K., Lewis, T. H., Bates, J. N., Robertson, T. P., et al. (2006a). 5-HT activates vagal afferent cell bodies in vivo: role of 5-HT2 and 5-HT3 receptors. Neuroscience 143, 273-287. doi: 10.1016/j.neuroscience.2006.07.032

Lacolley, P., Owen, J. R., Sandock, K., Lewis, T. H., Bates, J. N., Robertson, T. P., et al. (2006b). Occipital artery injections of 5-HT may directly activate the cell bodies of vagal and glossopharyngeal afferent cell bodies in the rat. Neuroscience 143, 289-308. doi: 10.1016/j.neuroscience.2006.08.047

Lee, J., Cummings, B. P., Martin, E., Sharp, J. W., Graham, J. L., Stanhope, K. L., et al. (2012). Glucose sensing by gut endocrine cells and activation of the vagal afferent pathway is impaired in a rodent model of type 2 diabetes mellitus. Am. J. Physiol. Regul. Integr. Comp. Physiol. 302, R657-R666. doi: 10.1152/ajpregu.00345.2011

Lee, P. G., Cai, F., and Helke, C. J. (2002). Streptozotocin-induced diabetes reduces retrograde axonal transport in the afferent and efferent vagus nerve. Brain Res. 941, 127-136. doi: 10.1016/S0006-8993(02)02645-8

Lee, P. G., Hohman, T. C., Cai, F., Regalia, J., and Helke, C. J. (2001). Streptozotocininduced diabetes causes metabolic changes and alterations in neurotrophin content and retrograde transport in the cervical vagus nerve. Exp. Neurol. 170, 149-161. doi: 10.1006/exnr.2001.7673

Levin, B. E., Dunn-Meynell, A. A., and Routh, V. H. (2001). Brain glucosensing and the K(ATP) channel. Nat. Neurosci. 4, 459-460. doi: 10.1038/87405

Liu, M. T., Seino, S., and Kirchgessner, A. L. (1999). Identification and characterization of glucoresponsive neurons in the enteric nervous system. J. Neurosci. 19, 10305-10317.

MacGregor, I. L., Gueller, R., Watts, H. D., and Meyer, J. H. (1976). The effect of acute hyperglycemia on gastric emptying in man. Gastroenterology 70, 190-196.

Martinez de la Pena y Valenzuela, I., Browning, K. N., and Travagli, R. A. (2004). Morphological differences between planes of section do not influence the electrophysiological properties of identified rat dorsal motor nucleus of the vagus neurons. Brain Res. 1003, 54-60. doi: 10.1016/j.brainres.2003.10.076

Mei, N. (1978). Vagal glucoreceptors in the small intestine of the cat. J. Physiol. 282, 485-506.

Mei, N. (1985). Intestinal chemosensitivity. Physiol. Rev. 65, 211-237.

Morton, A. P., and Hanson, P. J. (1984). Monosaccharide transport by the small intestine of lean and genetically obese (ob/ob) mice. Q. J. Exp. Physiol. 69, $117-126$.

Nosjean, A., Compoint, C., Buisseret-Delmas, C., Orer, H. S., Merahi, N., Puizillout, J. J., et al. (1990). Serotonergic projections from the nodose ganglia to the nucleus tractus solitarius: an immunohistochemical and double labeling study in the rat. Neurosci. Lett. 114, 22-26. doi: 10.1016/0304-3940(90)90422-6

Ordog, T., Takayama, I., Cheung, W. K., Ward, S. M., and Sanders, K. M. (2000). Remodeling of networks of interstitial cells of Cajal in a murine model of diabetic gastroparesis. Diabetes 49, 1731-1739. doi: 10.2337/diabetes.49. 10.1731

Raupach, T., and Ballanyi, K. (2004). Intracellular pH and KATP channel activity in dorsal vagal neurons of juvenile rats in situ during metabolic disturbances. Brain Res. 1017, 137-145. doi: 10.1016/j.brainres.2004.05.030

Raybould, H. E. (1998). Does your gut taste. Sensory transduction in the gastrointestinal tract. News Physiol. Sci. 13, 275-280.

Raybould, H. E. (1999). Nutrient tasting and signaling mechanisms in the gut. I. Sensing of lipid by the intestinal mucosa. Am. J. Physiol. 277, G751-G755.

Raybould, H. E. (2002). Visceral perception: sensory transduction in visceral afferents and nutrients. Gut 51(Suppl. 1), I11-I14. doi: 10.1136/gut.51.suppl_1.i11

Raybould, H. E., Glatzle, J., Robin, C., Meyer, J. H., Phan, T., Wong, H., and Sternini, C. (2003). Expression of 5-HT3 receptors by extrinsic duodenal afferents contribute to intestinal inhibition of gastric emptying. Am. J. Physiol. Gastrointest. Liver Physiol. 284, G367-G372. doi: 10.1152/ajpgi.00292.2001

Raymer, C. K., Park, H. S., Wishart, J. M., Kong, M.-F., Doran, S. M., and Horowitz, M. (2000). Effects of intraduodenal glucose and fructose on antropyloric motility and appetite in healthy humans. Am. J. Physiol. 278, R360-R366.

Rayner, C. K., Samsom, M., Jones, K. L., and Horowitz, M. (2001). Relationships of upper gastrointestinal motor and sensory function with glycemic control. Diabetes Care 24, 371-381. doi: 10.2337/diacare.24.2.371

Regalia, J., Cai, F., and Helke, C. (2002). Streptozotocin-induced diabetes and the neurochemistry of vagal afferent neurons. Brain Res. 938, 7-14. doi: 10.1016/S0006-8993(02)02456-3

Roosen, L., Boesmans, W., Dondeyne, M., Depoortere, I., Tack, J., and Vanden Berghe, P. (2012). Specific hunger- and satiety-induced tuning of guinea pig enteric nerve activity. J. Physiol. 590, 4321-4333. doi: 10.1113/jphysiol.2012.231134

Sayegh, A. I., Covasa, M., and Ritter, R. C. (2004). Intestinal infusions of oleate and glucose activate distinct enteric neurons in the rat. Auton. Neurosci. 115, 54-63. doi: 10.1016/j.autneu.2004.08.006

Schvarcz, E., Palmer, M., Aman, J., Horowitz, M., Stridsberg, M., and Berne, C. (1997). Physiological hyperglycemia slows gastric emptying in normal subjects and patients with insulin-dependent diabetes mellitus. Gastroenterology 113, 60-66. doi: 10.1016/S0016-5085(97)70080-5

Shapiro, R. E., and Miselis, R. R. (1985). The Central Organization of the Vagus Nerve Innervating the Stomach of the Rat. J. Comp. Neurol. 238, 473-488. doi: $10.1002 /$ cne.902380411

Shi, M., Jones, A. R., Ferreira, M. Jr., Sahibzada, N., Gillis, R. A., and Verbalis, J. G. (2005). Glucose does not activate nonadrenergic, noncholinergic inhibitory neurons in the rat stomach. Am. J. Physiol. Regul. Integr. Comp. Physiol. 288, R742-R750. doi: 10.1152/ajpregu.00561.2004

Shi, M., Jones, A. R., Niedringhaus, M. S., Pearson, R. J., Biehl, A. M., Ferreira, M. Jr., et al. (2003). Glucose acts in the CNS to regulate gastric motility during hypoglycemia. Am. J. Physiol. Regul. Integr. Comp. Physiol. 285, R1192-R1202. doi: 10.1152/ajpregu.00179.2003

Silver, I. A., and Erecinska, M. (1994). Extracellular glucose concentration in mammalian brain: continuous monitoring of changes during increased neuronal activity and upon limitation in oxygen supply in normo-, hypo-, and hyperglycemic animals. J. Neurosci. 14, 5068-5076.

Steinbusch, H. W. (1981). Distribution of serotonin-immunoreactivity in the central nervous system of the rat-cell bodies and terminals. Neuroscience 6 , 557-618. doi: 10.1016/0306-4522(81)90146-9

Steinbusch, H. W., and Nieuwenhuys, R. (1981). Localization of serotonin-like immunoreactivity in the central nervous system and pituitary of the rat, with special references to the innervation of the hypothalamus. Adv. Exp. Med. Biol. 133, 7-35. doi: 10.1007/978-1-4684-3860-4_1

Sykes, R. M., Spyer, K. M., and Izzo, P. N. (1994). Central distribution of substance $\mathrm{P}$, calcitonin gene-related peptide and 5-hydroxytryptamine in vagal sensory afferents in the rat dorsal medulla. Neuroscience 59, 195-210. doi: 10.1016/0306-4522(94)90110-4

Takahashi, T., Matsuda, K., Kono, T., and Pappas, T. N. (2003). Inhibitory effects of hyperglycemia on neural activity of the vagus in rats. Intens. Care Med. 29, 309-311. doi: 10.1007/s00134-002-1580-3

Thor, K. B., and Helke, C. J. (1989). Serotonin and substance P colocalization in medullary projections to the nucleus tractus solitarius: dual-colour immunohistochemistry combined with retrograde tracing. J. Chem. Neuroanat. 2, 139-148.

Tougas, G., Hunt, R. H., Fitzpatrick, D., and Upton, A. R. (1992). Evidence of impaired afferent vagal function in patients with diabetes gastroparesis. Pacing Clin. Electrophysiol. 15, 1597-1602. doi: 10.1111/j.1540-8159.1992. tb02939.x

Trapp, S., Ballanyi, K., and Richter, D. W. (1994). Spontaneous activation of $\mathrm{K}_{A T P}$ current in rat dorsal vagal neurones. Neuroreport 5, 1285-1288. doi: 10.1097/00001756-199406020-00033

Travagli, R. A., Hermann, G. E., Browning, K. N., and Rogers, R. C. (2006). Brainstem circuits regulating gastric function. Annu. Rev. Physiol. 68, 279-305. doi: 10.1146/annurev.physiol.68.040504.094635

Troy, A. E., and Browning, K. N. (2013). High fat diet decreases glucose-dependent modulation of 5-HT responses in gastrointestinal vagal afferent neurons. FASEB J. 27, 1158.3 . 
Vincent, K. M., Sharp, J. W., and Raybould, H. E. (2011). Intestinal glucoseinduced calcium-calmodulin kinase signaling in the gut-brain axis in awake rats. Neurogastroenterol. Motil. 23, e282-e293. doi: 10.1111/j.13652982.2011.01673.x

Wan, S., and Browning, K. N. (2008a). D-Glucose modulates synaptic transmission from the central terminals of vagal afferent fibers. Am. J. Physiol. Gastrointest. Liver Physiol. 294, G757-G763. doi: 10.1152/ajpgi.00576.2007

Wan, S., and Browning, K. N. (2008b). Glucose increases synaptic transmission from vagal afferent central nerve terminals via modulation of 5HT3 receptors. Am. J. Physiol. Gastrointest. Liver Physiol. 295, G1050-G1057. doi: 10.1152/ajpgi.90288.2008

Wang, X. Y., Huizinga, J. D., Diamond, J., and Liu, L. W. (2009). Loss of intramuscular and submuscular interstitial cells of Cajal and associated enteric nerves is related to decreased gastric emptying in streptozotocininduced diabetes. Neurogastroenterol. Motil. 21, 1095-1099. doi: 10.1111/j.13652982.2009.01336.x

Yagihashi, S., and Sima, A. A. (1986). Diabetic autonomic neuropathy in BB rat. Ultrastructural and morphometric changes in parasympathetic nerves. Diabetes 35, 733-743. doi: 10.2337/diab.35.7.733

Yettefti, K., Orsini, J. C., El Ouazzain, T., Himmi, T., Boyer, A., and Perrin, J. (1995). Sensitivity of the nucleus tractus solitarius neurons to induced moderate hyperglycemia, with special reference to catecholaminergic regions. J. Auton. Nerv. Syst. 51, 191-197.

Yettefti, K., Orsini, J.-C., and Perrin, J. (1997). Characteristics of glycemia-sensitive neurons in the nucleus tractus solitarii: possible involvement in nutritional regulation. Physiol. Behav. 61, 93-100. doi: 10.1016/S0031-9384(96)00358-7

Yoneda, S., Kadowaki, M., Kuramoto, H., Fukui, H., and Takaki, M. (2001). Enhanced colonic peristalsis by impairment of nitrergic enteric neurons in spontaneously diabetic rats. Auton. Neurosci. 92, 65-71. doi: 10.1016/S15660702(01)00317-4

Zhou, S. Y., Lu, Y. X., and Owyang, C. (2008). Gastric relaxation induced by hyperglycemia is mediated by vagal afferent pathways in the rat. Am. J. Physiol.
Gastrointest. Liver Physiol. 294, G1158-G1164. doi: 10.1152/ajpgi.00067. 2008

Zhu, J. X., Wu, X. Y., Owyang, C., and Li, Y. (2001). Intestinal serotonin acts as a paracrine substance to mediate vagal signal transmission evoked by luminal factors in the rat. J. Physiol. 530, 431-442. doi: 10.1111/j.1469-7793.2001. 0431k.x

Zhuo, H., Ichikawa, H., and Helke, C. J. (1997). Neurochemistry of the nodose ganglion. Prog. Neurobiol. 52, 79-107. doi: 10.1016/S0301-0082(97)00003-8

Zittel, T. T., De, G. R., Sternini, C., and Raybould, H. E. (1994). Fos protein expression in the nucleus of the solitary tract in response to intestinal nutrients in awake rats. Brain Res. 663, 266-270. doi: 10.1016/0006-8993(94)91272-6

Zsombok, A., Bhaskaran, M. D., Gao, H., Derbenev, A. V., and Smith, B. N. (2011). Functional plasticity of central TRPV1 receptors in brainstem dorsal vagal complex circuits of streptozotocin-treated hyperglycemic mice. J. Neurosci. 31, 14024-14031. doi: 10.1523/JNEUROSCI.2081-11.2011

Conflict of Interest Statement: The author declares that the research was conducted in the absence of any commercial or financial relationships that could be construed as a potential conflict of interest.

Received: 01 October 2013; accepted: 30 October 2013; published online: 26 November 2013.

Citation: Browning KN (2013) Modulation of gastrointestinal vagal neurocircuits by hyperglycemia. Front. Neurosci. 7:217. doi: 10.3389/fnins.2013.00217

This article was submitted to Autonomic Neuroscience, a section of the journal Frontiers in Neuroscience.

Copyright (C) 2013 Browning. This is an open-access article distributed under the terms of the Creative Commons Attribution License (CC BY). The use, distribution or reproduction in other forums is permitted, provided the original author $(s)$ or licensor are credited and that the original publication in this journal is cited, in accordance with accepted academic practice. No use, distribution or reproduction is permitted which does not comply with these terms. 